\title{
The Self Concept Change as a Tool for Developmental Academic Advising
}

\author{
Hasan Ugur \\ Psychological Counseling and Guidance, Fatih University, Turkey
}

Copyright $(\mathcal{C} 2015$ by authors, all rights reserved. Authors agree that this article remains permanently open access under the terms of the Creative Commons Attribution License 4.0 International License

\begin{abstract}
The main goals of academic advising are not only to improving social and academic success of students during academic year, but to improve the retention of the students with the successful interventions inside the educational system. Many areas of practice and research are mentioned in the scientific literature. One of them is improving students' self-concept in order to make them more successful at their academic concerns. However, except for self-efficacy, few researchers took other important aspects of self-concept into consideration. Self-perceived values are the target in our research. The present research is inspired from a practical work of students' developmental advising and shows how self-perceptions of the students regarding certain characteristics could be positively altered not only by using an intervention derived from Festinger's social comparison theory [1] but also application of positive psychology [2]. It has been found that students' self-perception is altered when students learned and improved their consciousness about how other peers perceive them regarding certain characteristics. Besides confirming once again the reality of social comparison theory in academic context, practical implications of the findings for developmental academic advising are concluded.
\end{abstract}

Keywords Developmental Academic Advising, Self-perception, Consciousness, Social Comparison, Positive Psychology

\section{Introduction}

\section{Self concept change as a tool for academic advising}

Educational Psychology research literature has identified many aspects of successful retention of the students inside the educational system, focusing among others, on building students' cognitive and motivational skills [3, 4], improving and measuring of student-advisor relationship [5], uncovering psychological factors that lead to academic success $[6,7]$ and improving the academic advising system
[8]. Particularly, with respect to self-concept, research has identified the fact that believes of self-efficacy differs in college population and they are always linked with positive consequences in academic settings [6, 7, 9-11]. However, although self-efficacy could be regarded as synthetic aspect of self-concept that has a proved utility in academic advising, less attention has been given to other aspects of self-concept that could be altered, for reaching the goals of academic advising, taking also into consideration the social milieu in which the student is inserted. One of the main goals of the developmental advising of students is the enhancement of the growth in the student [12-14] by rising awareness [14, 15] and the development of their potential $[2,16]$ according to their particular level of development. In order to accomplish its goals, every developmental advising system should take into consideration the student's own perceptions of the self as important for self exploration and thus for better informed decisions [17]. As noted by Corcoran and his colleagues "Self-perception, affective reactions, motivation, and behavior are all shaped by comparisons with others" [18, p.119]. The humanistic psychology notion of self-concept congruence shows also that well-being and growth usually take place when the individual has the chance to express his or her own unique self and that positive changing of self concept takes place in human encounter with significant others [19]. Festinger's theory of social comparison shows that self concept changes in relationship with the social environment that surrounds the individual [1]. Research carried in this tradition found that indeed that is the case, and that people posses a drive toward social self-evaluations which in many cases has the other proximate people as standards [1]. Students as well as clients of psychotherapy change their concept according to other's perceived characteristics [20, 21]. More recently, modern research using advanced statistical techniques showed the crucial impact of social environment [16, 22, 23] on students' self-concept development [24-26].

From the point of view of helping students and developing their talents during the educational process, "academic advising" should be a kind of system and process that makes students more conscious [27, 28] and motivated [29, 30] 
about their future educational plan [3]. Being conscious and motivated during the educational process in the university requires not only self monitoring, criticizing their behavior, and thinking about themselves [31] but also organizing their spare time in a useful way for themselves. As it is claimed by Kipnis [20], individual gets "feedback" from others. This kind of feedback could be provided not only by classmates of students but also academic advisors and professors who have the chance to observe the students [32-34]. In this respect, the advisor could perform an efficient advising and play a significant role in student's development and academic success. The theoretical basis for the study is developed from developmental academic advisement approaches [3] and the theory of social comparison processes proposed by Festinger [1].

It is apparent from the theoretical notions presented above that it is assumed that perceived differences are based upon observations and comparisons of behavior, and that the person's perception and evaluations in turn have consequences that determine further behavior. This means that the individual's perception of others who are important to him has very real consequences for the way he behaves or attempts to behave [20]. Recent research not only recognizes theoretically and empirically that social comparison theory has a high degree of truth but also that there is a tendency that social comparison could be considered as one of the "basic phenomena underlying human social life" [35] (pp.472). One can see from our statements how important it is in educational settings to show and research this processes that can be used for practical application in counseling and advising. Additionally, more recent literatures show that believes of self-efficacy[10,11,36,37], that have been found very important in academic tasks, are built always in relationship with perception of close fellow human beings behavior [38]. Therefore, our main assumption is that students confronted with perceptions that others have upon their behavior tend to change their self-perceptions in time, as a function of comparisons they make between their own perception and the conscious notion of significant (colleagues) other's perceptions about them.

\section{Rationale of the Study}

To improve students' social and academic success with successful intervention of advisor is the main part of academic advising in universities. Self-concept change of students in a better way is supposed to make the relation between advisor and advisee effective and productive. With the methodology of this study,

Students learn:

- how they perceive themselves

- how they are perceived by their classmates confidentially

- what their behavioral status is among classmates comparatively. It is a kind of innate behaviour [1]
- their own perceptional strengths perceived by classmates.

- sharing with their advisors their perceptual behavioral result which are received as a feedback from their classmates.

Learning as a feedback from classmates the performed behavior results in class or during the relationship with others through semester help and motivate students to get better. It also causes improving consciousness and self-concept change of students. And so, students have chance to apply their advisors to get more information related with their own concerns. In this respect;

\section{Advisor:}

- have information about students behavior.

- get advantages by learning the situation of students in advance to think more to be helpful for students.

- prepare themselves emotionally and intellectually for the processes of advising.

\section{Objectives}

- To concentrate students on self-perception with respect to the rules of positive psychology $[2,39]$.

- To use social comparison theory to improve consciousness.

- To share perceptional behavioral results with advisors to get effective feedback to get better.

\section{Method}

\section{Participants}

Participants of this study where 57 students who were majoring in Social Sciences, Engineering and Humanities, with the following demographic characteristics: Age 20-24 years old $(M=23, S D=2.34)$, $45 \%$ girls, $55 \%$ boys, $100 \%$ Turkish ethnicity and nationality. Subjects with missing data were removed from analyses and we conducted analyses only when subjects have all questions answered.

\section{Measures}

For this research we constructed a special questionnaire. Universal values extracted from psychological literature were selected as characteristics of students that they can perceive in themselves as well as in others. They don't have in our opinion clearly defined objectivity, so people might rely on other's opinion in the process of evaluation of self [1]. These characteristics are in our opinion important for the current educational tasks in which students are involved. The values/characteristics were studying hard [40], being successful [41,42], being ethical, being well mannered, being respectful to others [43], being patient [44]. In this way we consider that the questionnaire had adequate content validity. The questionnaire had also the names of students from same class included. There were five requests and very important attention points on the questionnaire form for students. They were: 1) "Do not evaluate a classmate if you 
are not familiar with his/her behavior"; 2) "Only score the characteristics for which you have information"; 3) "Be aware that the results may be helpful to your classmates"; 4) "Do not ask for information from others while you are completing the form"; 5) "To evaluate yourself, please take note of your evaluations for later comparison". In the questionnaire form, 5-point Likert-type scale $(1=$ completely disagree, $5=$ completely agree) was used for rating the strength of each characteristic. We also calculated "Pearson r" for inter-rater reliability and the coefficients showed quite high relationships because they ranged from 0.72(being patient) to 0.82 (being successful).

\section{Procedure}

An invitation email which explained shortly the application was sent to all students who existed on the list taken from the registrar's office of the university. The list included not only names and surnames of students but also email addresses. All years, except freshmen were there in the list of students (It is believed that freshmen had not enough observation on other's behavior in a short time). They were sent questionnaire forms and consent forms which explained all rights of participants. Emails were sent only to the students of classes where there were more than ten students. And if the number of returned emails from one class was less than ten, they were not included in the study. Since, one student had to be evaluated by at least ten classmates.
Students returned by email after they filled forms out. The rule was that students would evaluate only the students whose characteristics they had observed and had an idea about. All the data collected from participants were evaluated and the results were shown on graphs. There were two graphs on the results paper. On the first graph, the situation of each own characteristic for each student was made clear. The second graph, which was resulted if the student was rated by ten classmates, which helped students compare himself/herself with others. The result graphs were sent to students individually and confidentially. During the application, students were sent emails to help them understand how they would comment on the results and what they could do as a second step. After all students received their own results, students were supposed to think why and how they were perceived as on the graphs. And then, with additional emails all students were motivated to think about how they should behave with their classmates during the semester. At the end of the semester, the questionnaires of application were repeated again. The same questionnaire forms were sent to all participants and they filled out and returned them back again. The results of the second application were included with the result of the first application in order to show the changes of students' own behaviors. Consequently, the participants were received the emails which included all results as a graph comparatively.

Table 1. Descriptive Statistics and t-test results for the selected values/characteristics

\begin{tabular}{|c|c|c|c|c|c|c|c|c|c|}
\hline \multirow{2}{*}{ Value } & \multicolumn{3}{|c|}{ Pre-intervention } & \multicolumn{3}{c|}{ Post-intervention } & \multicolumn{1}{c|}{$\begin{array}{c}\text { 95\% CI for } \\
\text { Mean } \\
\text { Difference }\end{array}$} & & \\
\hline & $M$ & $S D$ & $N$ & $M$ & $S D$ & $N$ & & $r$ & $t$ \\
\hline Ethical & 3.27 & .81 & 49 & 3.41 & .70 & 49 & $-.26-.03$ & $.86^{* *}$ & $-2.45^{* *}$ \\
\hline Patient & 3.00 & .74 & 38 & 3.13 & .78 & 38 & $-.24-.02$ & $.90^{* *}$ & $-2.37^{* *}$ \\
\hline Respectful & 3.27 & .62 & 45 & 3.42 & .69 & 45 & $-.28-.03$ & $.80^{* *}$ & $-2.46^{* *}$ \\
\hline Studies hard & 3.15 & 1.07 & 52 & 3.31 & 1.09 & 52 & -.35 .04 & $.79^{* *}$ & -1.59 \\
\hline Successful & 3.17 & .88 & 48 & 3.17 & .86 & 48 & -.10 .10 & $.92^{* *}$ & .00 \\
\hline Well mannered & 3.45 & .85 & 44 & 3.59 & .92 & 44 & -.29 .02 & $.84^{* *}$ & $-1.77^{*}$ \\
\hline
\end{tabular}

$* \mathrm{p}<.05 . \quad * * \mathrm{p}<.01$. 


\section{Results}

We have conducted paired $t$ tests on first and second set of scores resulted from administering of the questionnaires. For this purpose we used a correction based on Bonferonni correction, thus, setting the level of significance to 0.01 , to guard against both type I and type II errors. The results of the paired $t$ tests are shown in the table 1 above.

As we can see from the data displayed in Table 1, there are statistically significant differences, at the .01 significance level, in the pre-intervention to post-intervention scores for 3 of the selected values/characteristics. Respectively, results show that the self perception intensity of the characteristics: being ethical [pre M:3.27, SD:0.81 - post M:3.41, SD:0.70] $\mathrm{t}(48)=2.45, \mathrm{p}<.01$; being patient [pre M:3.00, SD:0.74 - post $\mathrm{M}: 3.13$, SD:0.78] $\mathrm{t}(37)=2.37, \mathrm{p}<.01$ and being respectful [pre M:3.27, SD:0.62 - post M:3.42, SD:0.69] $\mathrm{t}(44)=2.46$, $\mathrm{p}<.01$ were all significantly increased and the characteristics of being well-mannered [pre M:3.45, SD:0.85 - post M:3.59, SD:0.92] $\mathrm{t}(43)=1.77, \mathrm{p}<.05$; studies hard [pre M:3.15, $\mathrm{SD}: 1.07$ - post M:3.31, SD:1.09] $\mathrm{t}(51)=1.59, \mathrm{p}<.05$; and being successful [pre M:3.17, SD:0.88 - post M:3.17, SD:0.86] $\mathrm{t}(48)=0, \mathrm{p}<.05$ haven't reached significance at the desired level. We can conclude from the data that for the half of the characteristics the intervention that enhanced social comparisons had an effect on students' self-perceptions.

Table 2 presents the corresponding effect sizes that show how much of the variance of changing of the dependent variable i.e. self perception of the selected characteristics can be explained by the intervention.

As we can see from the table below, the effect sizes are very small. However the first three greatest effect size belongs to the characteristics being respectful, .22, being ethical, .18, and being patient, .17; and the other characteristics' effect sizes are being well mannered, .15, studying hard, .14, and being successful has no effect size.

Table 2. Effect sizes of the intervention

\begin{tabular}{|c|c|}
\hline Value/Characteristic & Cohen's $d$ \\
\hline Ethical & -.18 \\
\hline Patient & -.17 \\
\hline Respectful & -.22 \\
\hline Studies hard & -.14 \\
\hline Successful & .00 \\
\hline Well mannered & -.15 \\
\hline
\end{tabular}

\section{Conclusions}

The findings outlined in this research indicate that finding out how students are perceived by the classmates not only motivates and make students conscious regarding their behavior but also causes self-awareness and change in self-perception for several of the variables included. We can conclude from the data that for the half of the characteristics the intervention that enhanced social comparisons, had an effect on students self-perception The results support, as many other studies, the fact that social comparison's processes do work [1]. The importance of social comparison processes has also been shown for school performance [45] which is why our study show that social comparison's processes could be used as a tool of academic advisors in positively changing the self concept's of students. Keeping up with the traditional research on social comparison's of characteristics, we can admit once again that important values that are present in students self perception and that shaped students behaviors cannot be easily altered without reference to other peers [1].

We could also broadly mention the underlying phenomenon of changing self perception present in our intervention, that is, students are made conscious about other's perception about them and as a results a motivational drive have influenced the positive change in self-perception. This could have important practical consequences and we encourage other researcher's not only to discover new ways in which positive social comparisons that alters the students self perception are enhanced but also to develop our system, as well as practitioners to apply our method in practical work of advising. Based on our results and previous literature we also consider that social comparison processes must be taking into account when the advisors wish to alter other aspects of self-concept, like self-efficacy believes, which have been shown very important for academic success $[6,7$, $36,46]$. Of course, the values of studying hard and being successful have not been changed and we believe that this kind of self-perception is harder to change because they have a more direct reference to behavior. It might be suggested for future researchers to change them better. Also, the study though experimental has been open to a diverse confounding, especially that there was a long period between the two administrations of questionnaires. We strongly encourage other scientists to develop better research designs that could also have practical applied values for students advising work.

\section{REFERENCES}

[1] Festinger, L., A Theory of Social Comparison Processes. Human Relations, 1954. 7: p. 117.

[2] Seligman, M.E.P. and M. Csikszentmihalyi, Positive psychology: An introduction. American Psychologist, 2000. 55(1): p. 5-14.

[3] Wiseman, C. and H. Messitt, Identifying components of a successful faculty-advisor program. NACADA Journal 2010. 30(2): p. 35-52.

[4] Drake, J.K., The role of academic advising in student retention and persistence. About Campus, 2011. 16(3): p. 8-12.

[5] Bitz, K., Measuring advisor relationship perceptions among first-year students at a small midwestern university. NACADA Journal 2010. 30(2): p. 53-64. 
[6] Shaw, E.J. and S. Barbuti, Patterns of persistence in intended college major with a focus on STEM majors. NACADA Journal 2010. 30(2): p. 19-34.

[7] Cunningham, K.E. and A.W. Smothers, The effect of self-efficacy and psychosocial development on major-changing behavior. NACADA Journal, 2010. 30(2): p. 65-71.

[8] Keeling, S., The influence of the CAS Standards on academic advisors and advising programs. NACADA Journal, 2010. 30(2): p. 9-17.

[9] Bandura, A., Perceived Self-Efficacy in Cognitive Development and Functioning. Educational Psychologist, 1993. 28(2): p. 117.

[10] Morton, S., A. Mergler, and P. Boman, Managing the Transition: The Role of Optimism and Self-Efficacy for First-Year Australian University Students. Australian Journal of Guidance \& Counselling, 2014. 24(1): p. 90-108.

[11] Sungok, S. and A. Ryan, Changes in Self-Efficacy, Challenge Avoidance, and Intrinsic Value in Response to Grades: The Role of Achievement Goals. Journal of Experimental Education, 2005. 73(4): p. 333-349.

[12] Kadar, R.S., A Counseling Liaison Model of Academic Advising. Journal of College Counseling, 2001. 4(2): p. 174-178.

[13] Liu, Y. and A.C. Yin, Assessing personal growth. New Directions for Institutional Research, 2010. 2010: p. 111-123.

[14] Ugur, H., M. Steven, and P. Madalin, Self-Awareness and Personal Growth: Theory and Application of Bloom's Taxonomy (under review). 2013.

[15] Adamska, K. and N. Kosakowska-Berezecka, The role of self-awareness in enhancing cooperative behaviour among students. Citizenship Teaching \& Learning, 2013. 8(2): p. 233-248.

[16] Raushi, T.M., Developmental Academic Advising. New Directions for Community Colleges, 1993(82): p. 5-19.

[17] Gordon, V.N., The Undecided Student: A Developmental Perspective. Personnel \& Guidance Journal, 1981. 59(7): p. 433.

[18] Corcoran, K., J. Crusius, and T. Mussweiler, Social Comparison: Motives, standards and mechanisms. . Theories in social psychology. 2011, Oxford UK: Wiley-Blackwell.

[19] Rogers, C.R., On becoming a person. 1961, Boston: Houghton Mifflin.

[20] Kipnis, D.M., Changes in self concepts in relation to perceptions of others. Journal of Personality, 1961. 29(4): p. 449.

[21] Harrison, E., What Constitutes Good Academic Advising? Nursing Students' Perceptions of Academic Advising. Journal of Nursing Education, 2009. 48(7): p. 361-366.

[22] Pizzolato, J.E., Advisor, teacher, partner: Using the learning partnerships model to reshape academic advising. About Campus, 2008. 13(1): p. 18-25.

[23] Shane, D., Academic Advising in Higher Education: A Developmental Approach for College Students of AIIAges.
NACADA Journal, 1981. 1(2): p. 12-23.

[24] Wilson, H.E., A model of academic self-concept: Perceived difficulty, social comparison, and achievement among academically accelerated secondary school students. Doctoral Dissertations, Paper AAI3360711., 2009.

[25] Blanton, H., et al., When better-than-others compare upward: Choice of comparison and comparative evaluation as independent predictors of academic performance. Journal of Personality and Social Psychology, 1999. 76(3): p. 420-430.

[26] Thompson, S.C., The Role of Personal Control in Adaptive Functioning. 2002.

[27] Inzlicht, M., B.D. Bartholow, and J.B. Hirsh, Opinion: Emotional foundations of cognitive control. Trends in Cognitive Sciences, 2015. 19: p. 126-132.

[28] Andela, M., L. Auzoult, and D. Truchot, An exploratory study od self-consciousness and emotion-regulation strategies in health care workers. Psychological Reports, 2014. 115(1): p. 106-114.

[29] Berndt, T.J., A.E. Laychak, and K. Park, Friends' Influence on Adolescents' Academic Achievement Motivation: An Experimental Study. Journal of Educational Psychology, 1990. 82(4): p. 664.

[30] Feldman, K.A. and M.B. Paulsen, Faculty Motivation: The Role of a Supportive Teaching Culture. New Directions for Teaching \& Learning, 1999. 1999(78): p. 71.

[31] Duval, S. and R.A. Wicklund, A theory of objective self-awareness. 1972, New York: Academic Press.

[32] Wininger, S. and P. Birkholz, Sources of Instructional Feedback, Job Satisfaction, and Basic Psychological Needs. Innovative Higher Education, 2013. 38(2): p. 159-170.

[33] Shannon, D.M. and D.J. Twale, Use of instructional feedback and modification methods among university faculty. Assessment \& Evaluation in Higher Education, 1996. 21(1): p. 41.

[34] Hoban, G. and G. Hastings, Developing different forms of student feedback to promote teacher reflection: A 10-year collaboration. Teaching \& Teacher Education, 2006. 22(8): p. 1006-1019.

[35] Buunk, B.P. and M. Thomas, New directions in social comparison research. European Journal of Social Psychology, 2001. 31(5): p. 467-475.

[36] Pajares, F., Self-Efficacy Beliefs in Academic Settings. Review of Educational Research, 1996. 66(4): p. 543-578.

[37] Rakauskiene, V. and A. Dumciene, Alteration of Adolescent Self-Efficacy When Applying Brief Counseling at School. Social Behavior \& Personality: an international journal, 2013. 41(6): p. 893-899.

[38] Dunning, D. and A.F. Hayes, Evidence for egocentric comparison in social judgment. Journal of Personality and Social Psychology, 1996. 71: p. 213-229.

[39] Seligman, M.E.P., Coaching and Positive Psychology. Australian Psychologist, 2007. 42(4): p. 266-267.

[40] George, D., et al., Time diary and questionnaire assessment of factors associated with academic and personal success among university undergraduates. 2008, Taylor \& Francis Ltd. p. 706. 
[41] Gerber, P.J., R. Ginsberg, and H.B. Reiff, Identifying alterable patterns in employment success for highly successful adults with learning disabilities. Journal of Learning Disabilities, 1992. 25(8): p. 475-487.

[42] Gerber, P.J., R.J. Ginsberg, and R.S.o.E. Virginia Commonwealth Univ, Identifying Alterable Patterns of Success in Highly Successful Adults with Learning Disabilities. Executive Summary. 1990.

[43] Kinnier, R.T., J.L. Kernes, and T.M. Dautheribes, $A$ Short List of Universal Moral Values. Counseling \& Values, 2000.
45(1): p. 4.

[44] Norling, P.M., In Innovation, Is Patience a Virtue? Research Technology Management, 2009. 52(3): p. 18-23.

[45] Trautwein, U., et al., Within-school social comparison: how students perceive the standing of their class predicts academic self-concept. Journal of Educational Psychology, 2009(4): p. 853.

[46] Young-Jones, A.D., et al., Academic advising: does it really impact student success? Quality Assurance in Education, 2013. 21(1): p. 7-19. 